Supplement of The Cryosphere, 10, 2027-2041, 2016

http://www.the-cryosphere.net/10/2027/2016/

doi:10.5194/tc-10-2027-2016-supplement

(C) Author(s) 2016. CC Attribution 3.0 License.

(c) (i)

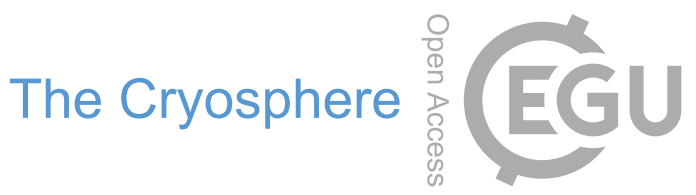

Supplement of

\title{
Sea-ice indicators of polar bear habitat
}

\section{Harry L. Stern and Kristin L. Laidre}

Correspondence to: Harry L. Stern (harry@apl.washington.edu)

The copyright of individual parts of the supplement might differ from the CC-BY 3.0 licence. 


\section{Supplement}

\section{S1. Daily Sea-Ice Area}
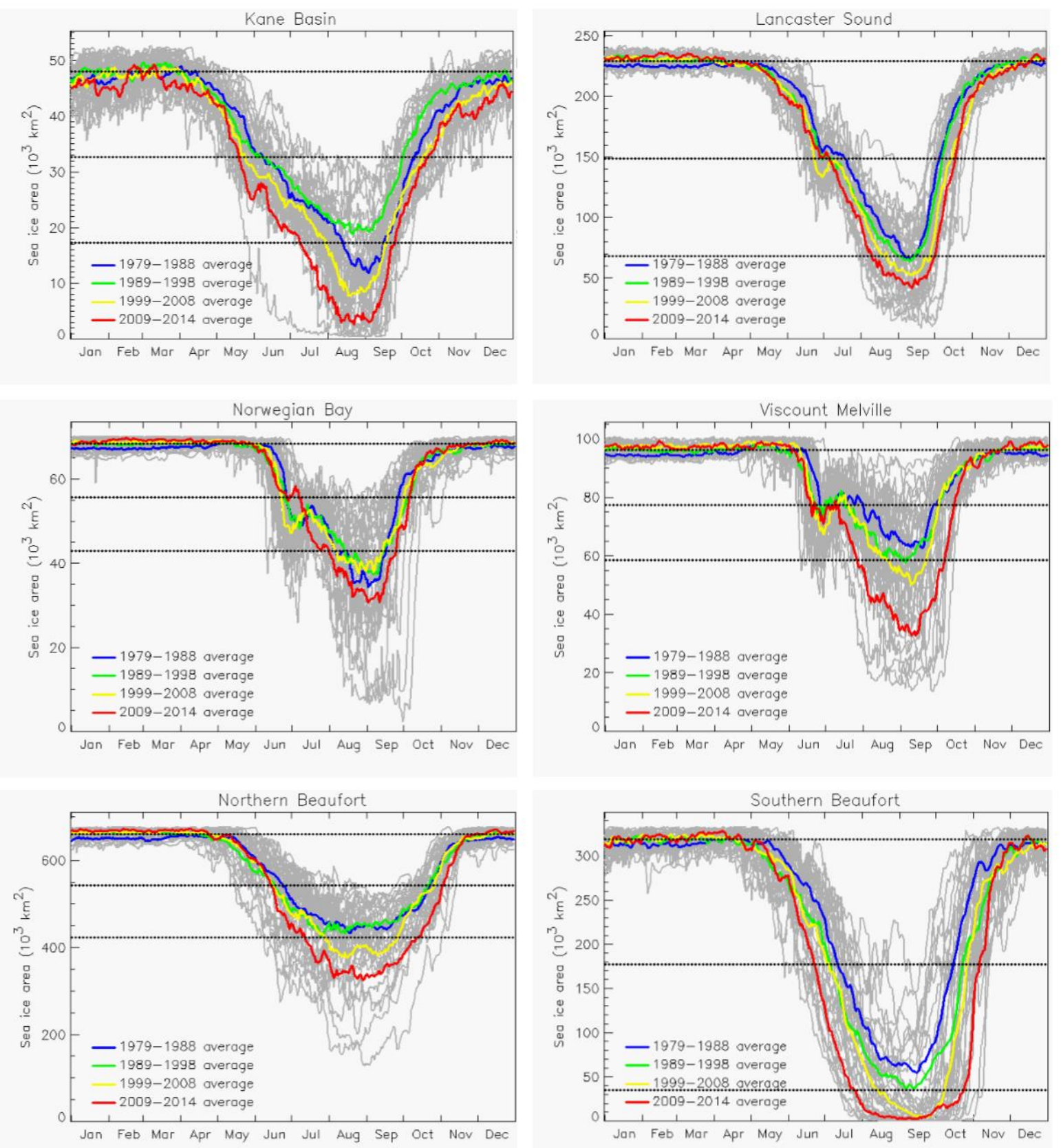

5 Figure S1. Daily sea-ice area, January-December, 1979-2014 (gray curves), by region (all depths). Colored curves are decadal averages as indicated. Upper horizontal dotted line is average sea-ice area in March; lower horizontal dotted line is average sea-ice area in September; middle horizontal dotted line is threshold for determining dates of spring sea-ice retreat and fall sea-ice advance. See Fig. 2 for Baffin Bay region. See Fig. 1 and Table 1 for locations of regions. 

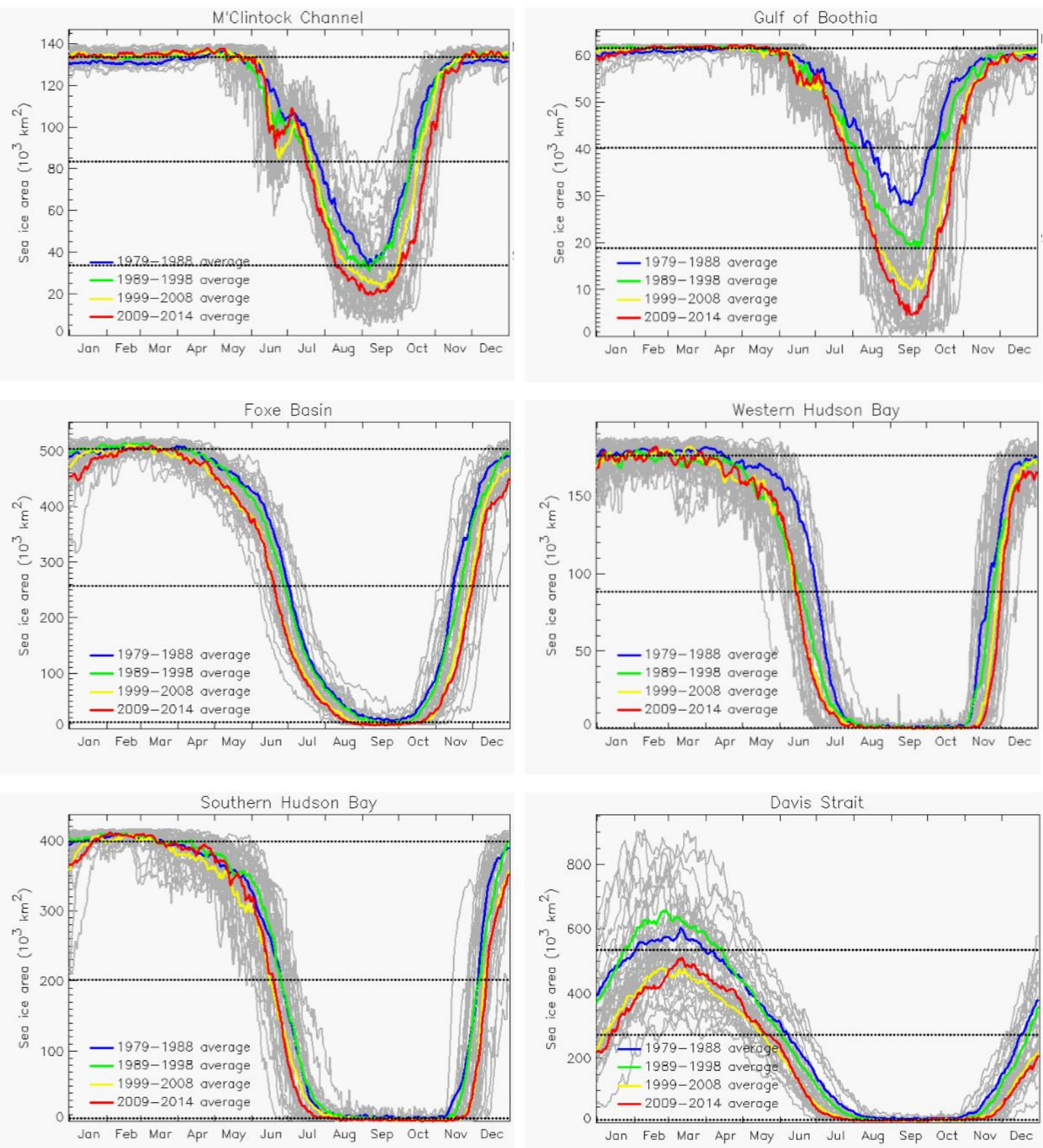

Figure S1 (continued). Daily sea-ice area by region. 

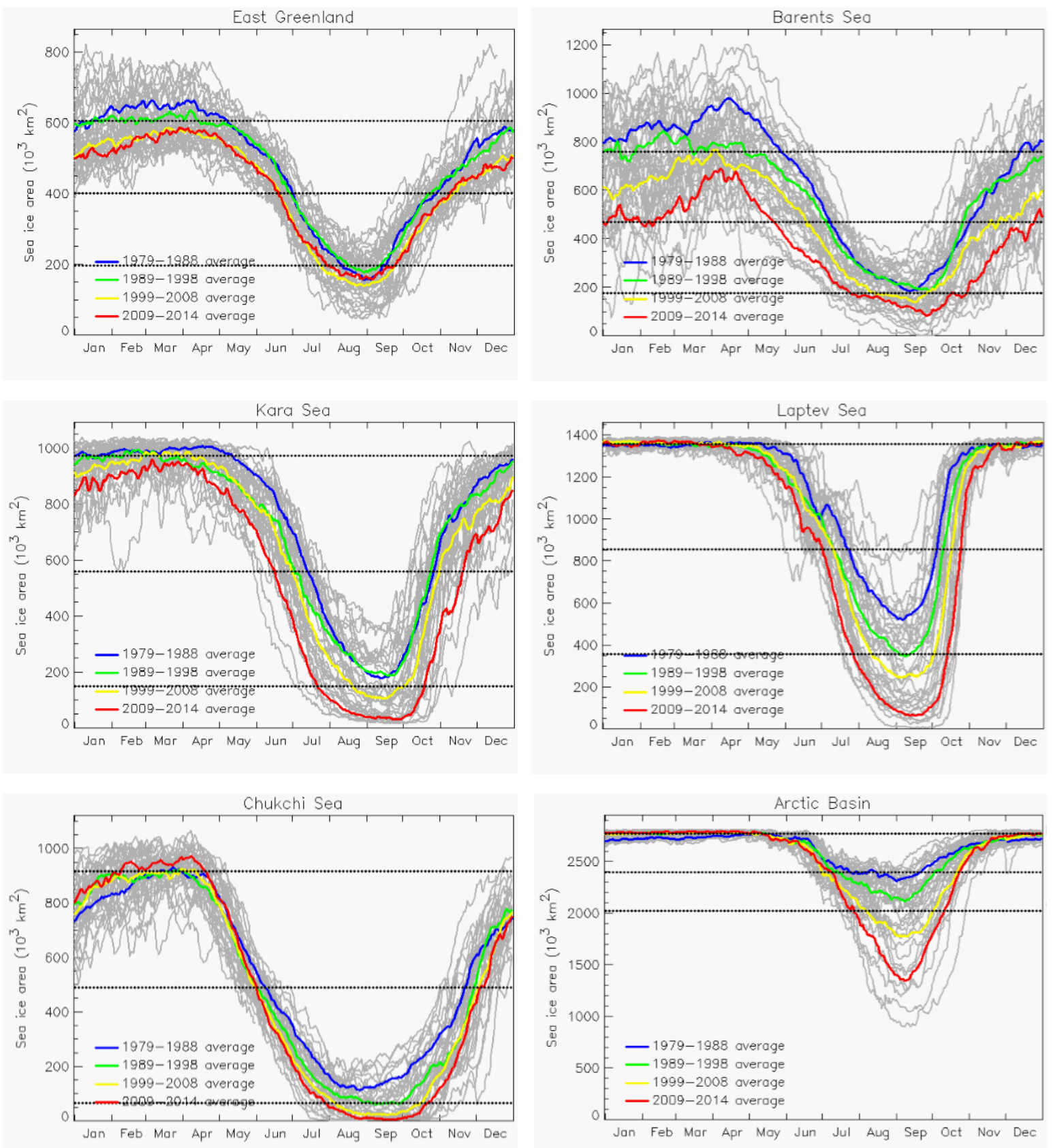

Figure S1 (continued). Daily sea-ice area by region. 

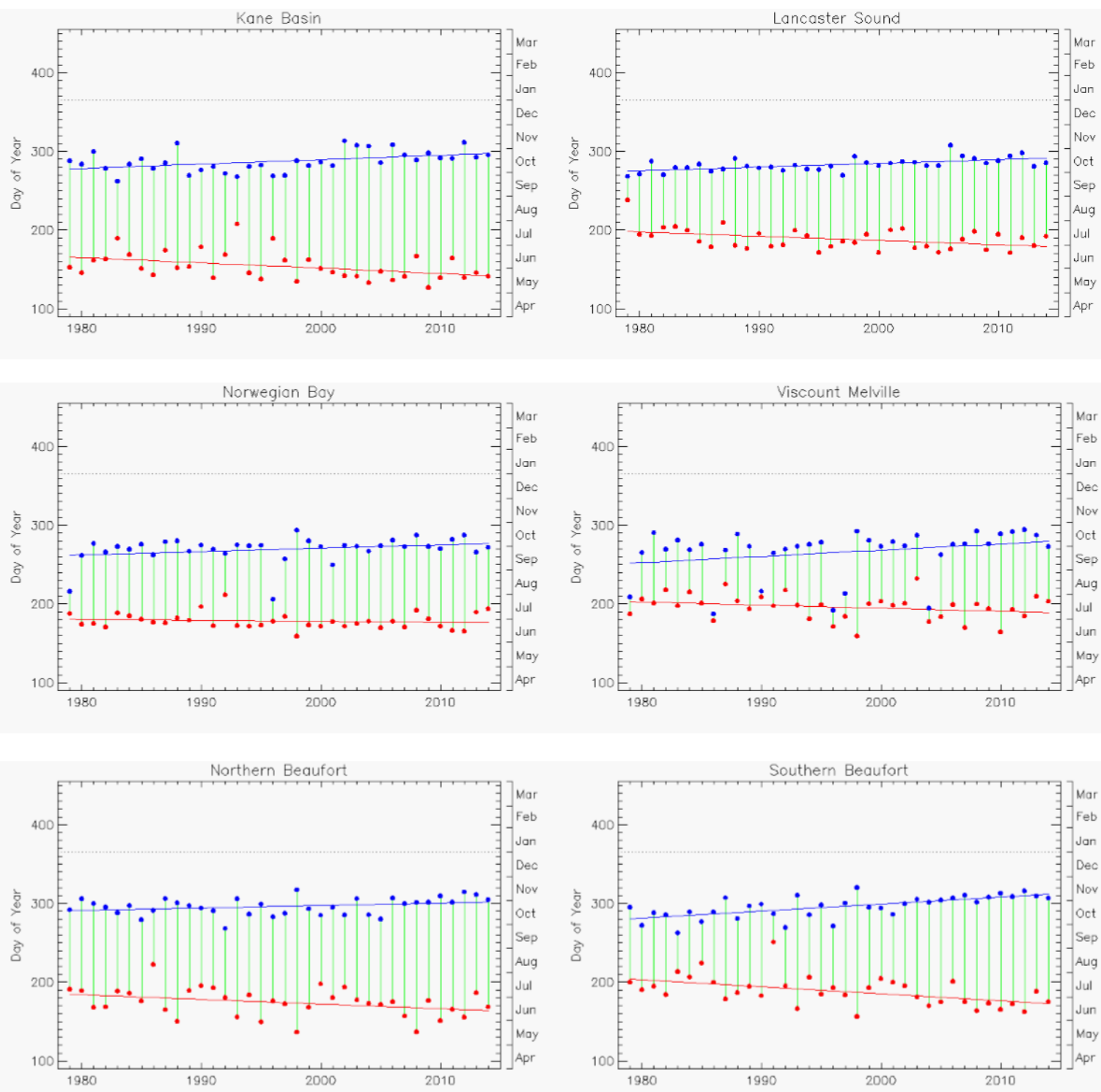

Figure S2. Dates of sea-ice retreat (red) and sea-ice advance (blue) for 1979-2014, by region (all depths). The red and blue lines are least-squares fits. The vertical green lines indicate the time interval between retreat and advance (i.e., length of summer season). See Fig. 4 for Baffin Bay region. See Table 3 for trends. 

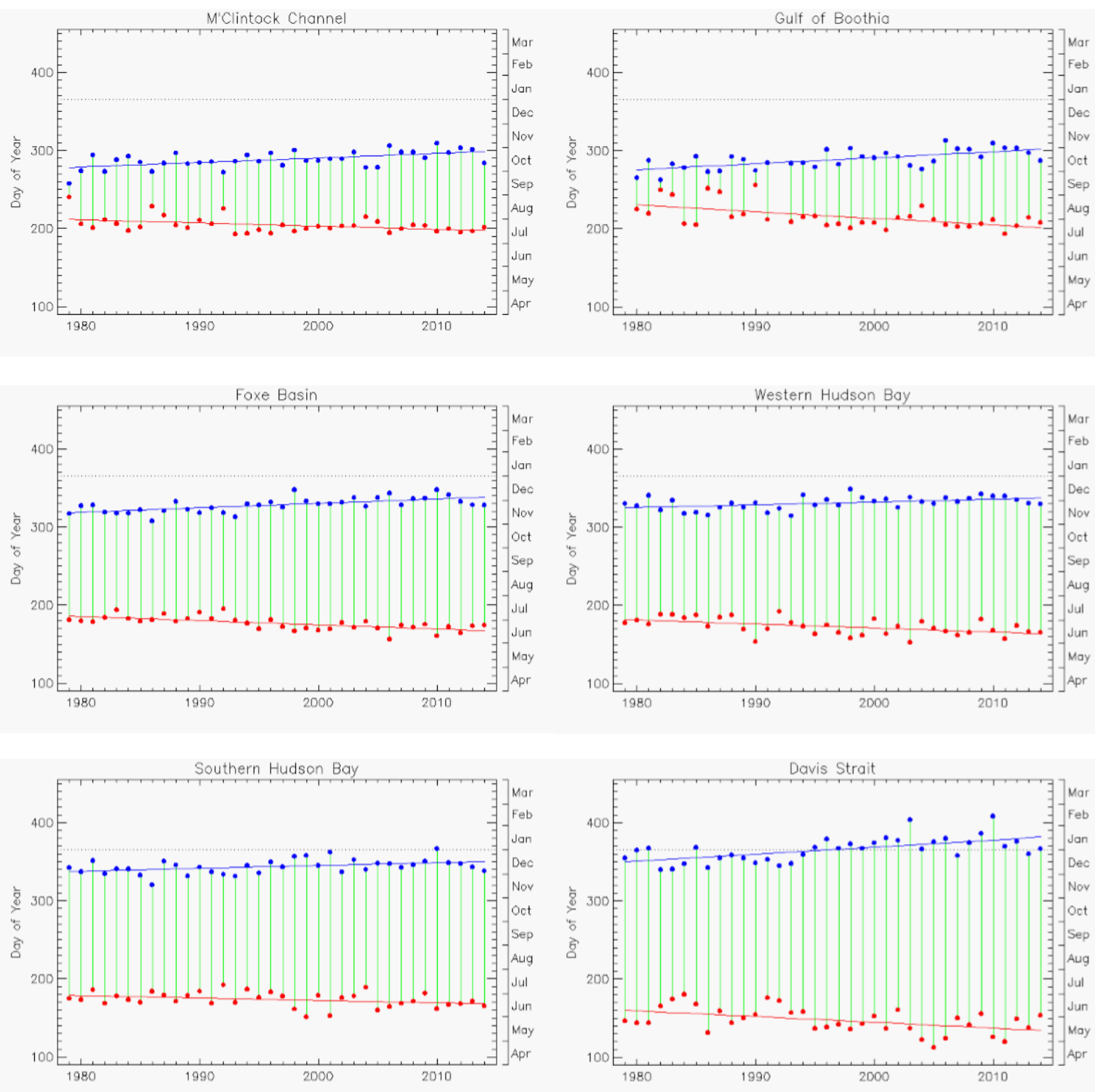

Figure S2 (continued). Dates of sea-ice retreat and advance, by region. 

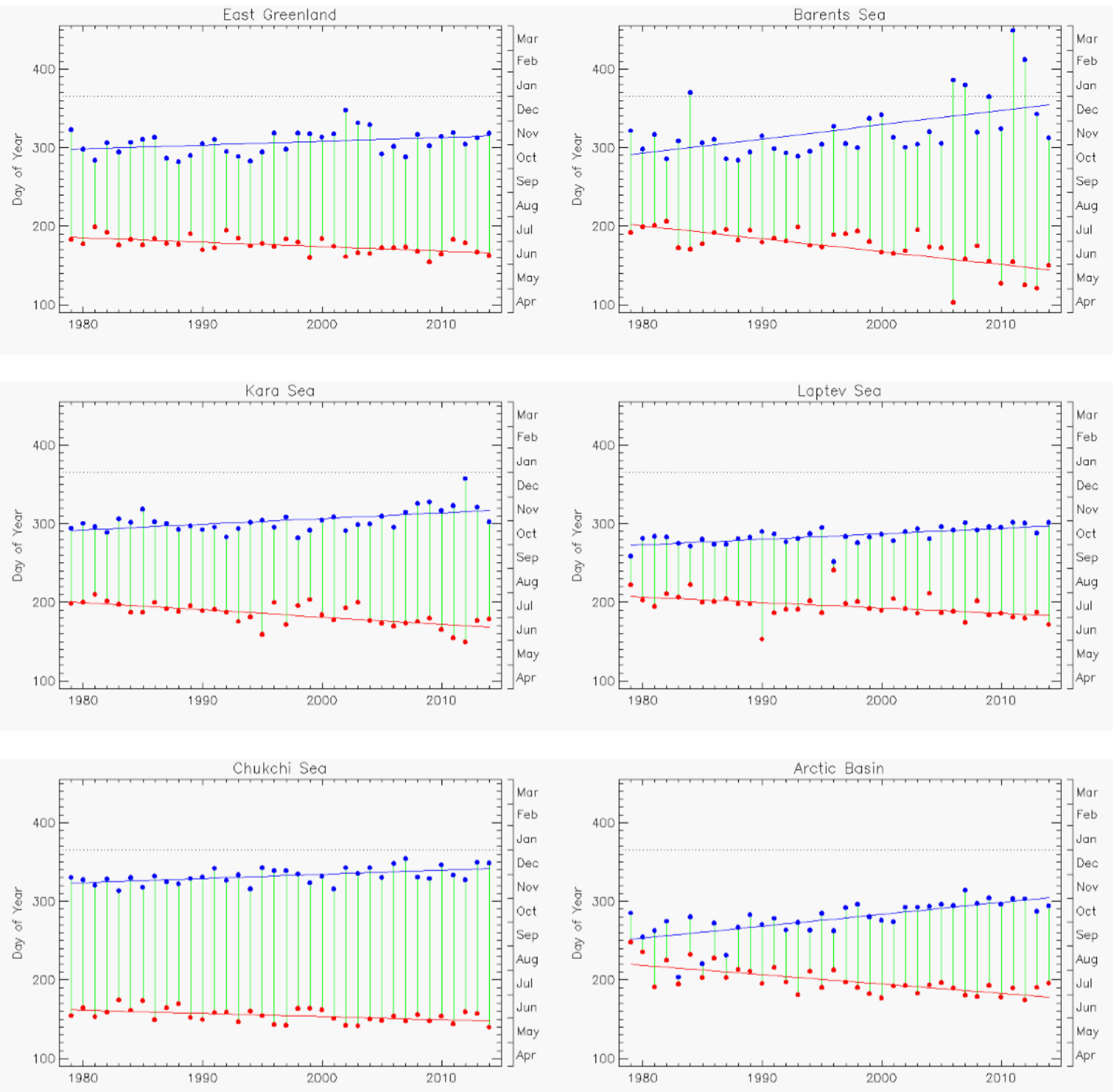

Figure S2 (continued). Dates of sea-ice retreat and advance, by region. 

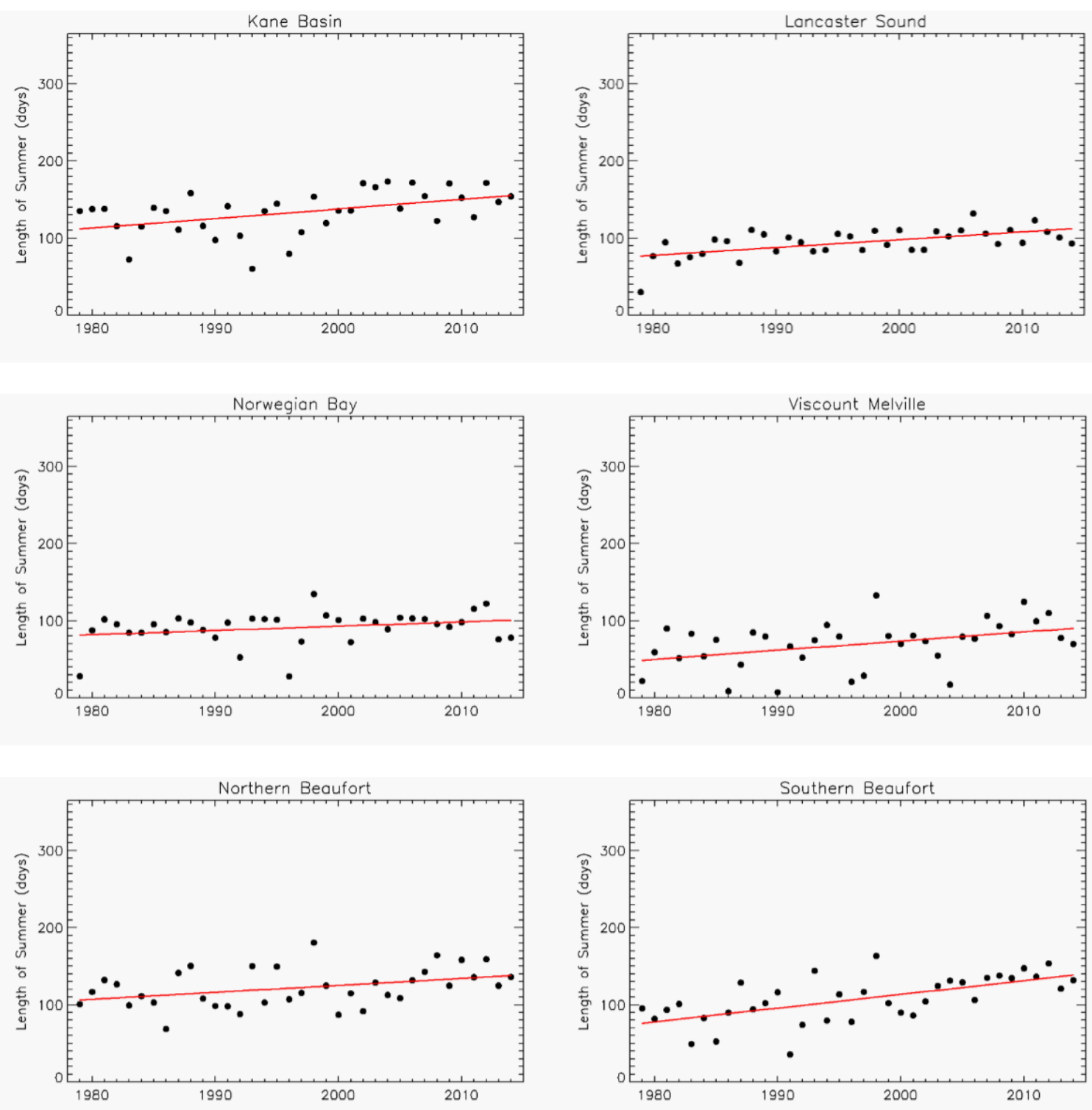

Figure S3. Length of the summer season (from spring sea-ice retreat to fall sea-ice advance) vs. year, by region (all depths), with least-squares line in red. See Fig. 5 for Baffin Bay region. See Table 3 for trends. 

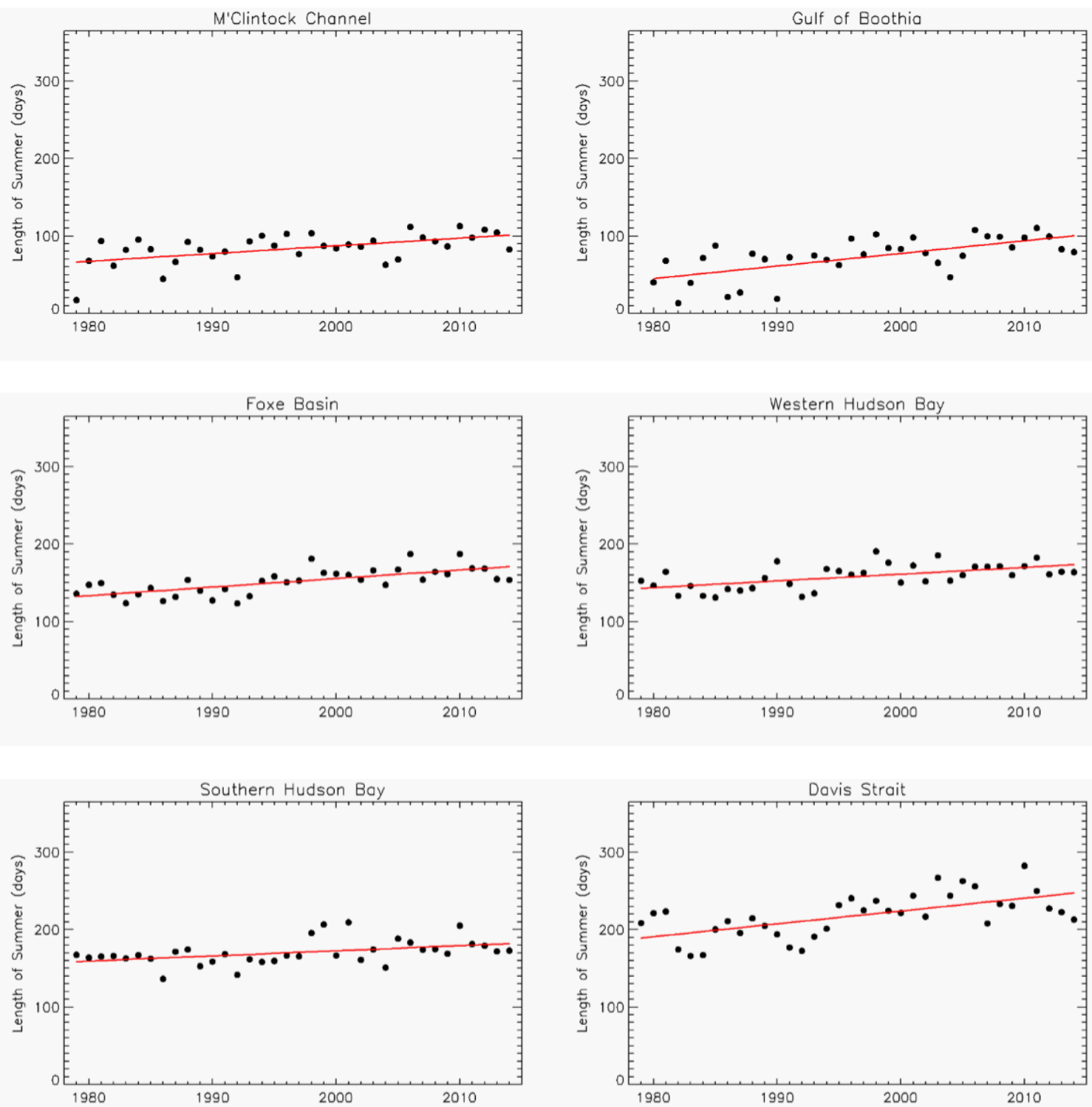

Figure S3 (continued). Length of the summer season, by region. 

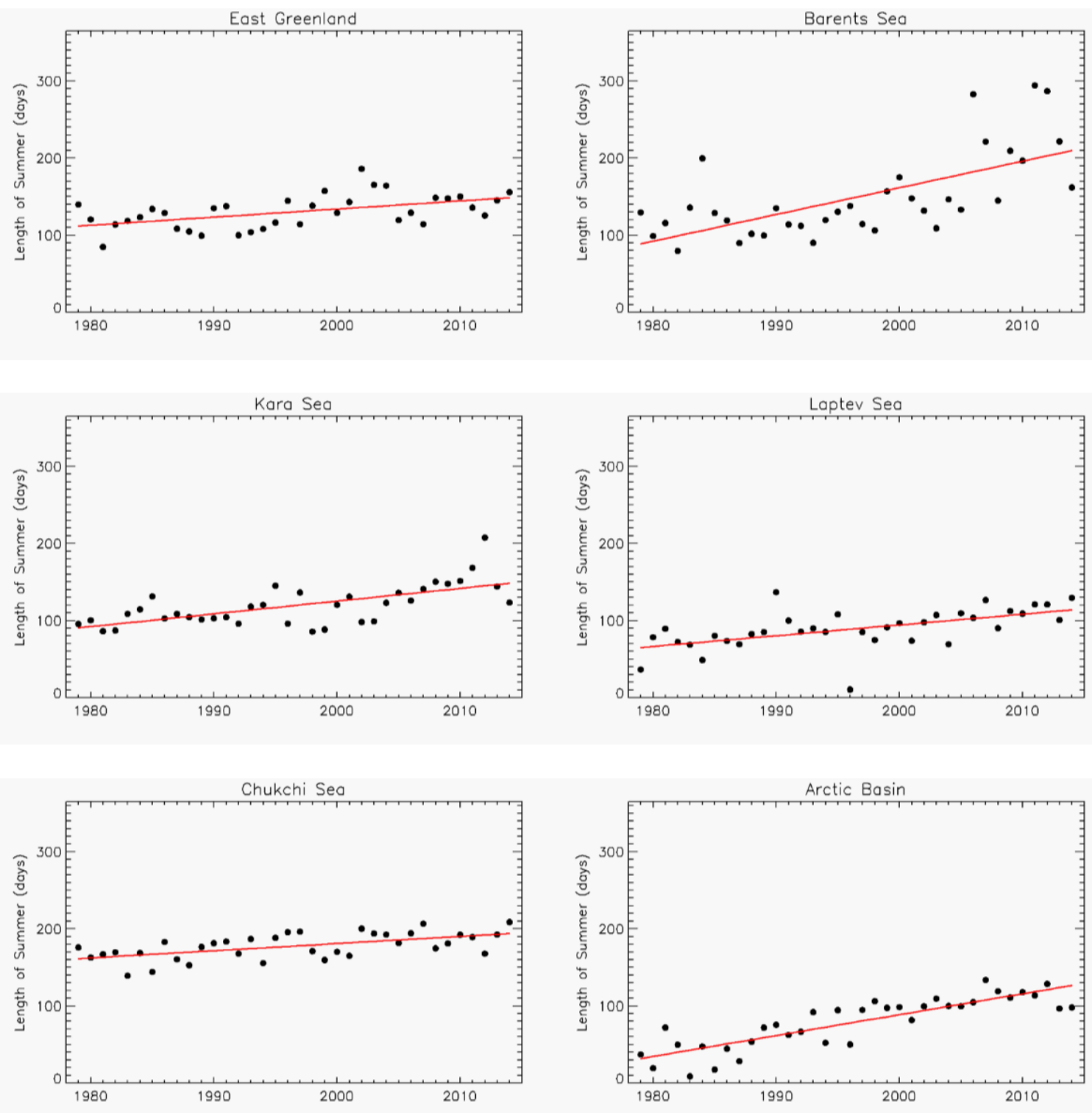

45 Figure S3 (continued). Length of the summer season, by region. 


\section{S4. Summer Sea-Ice Concentration}
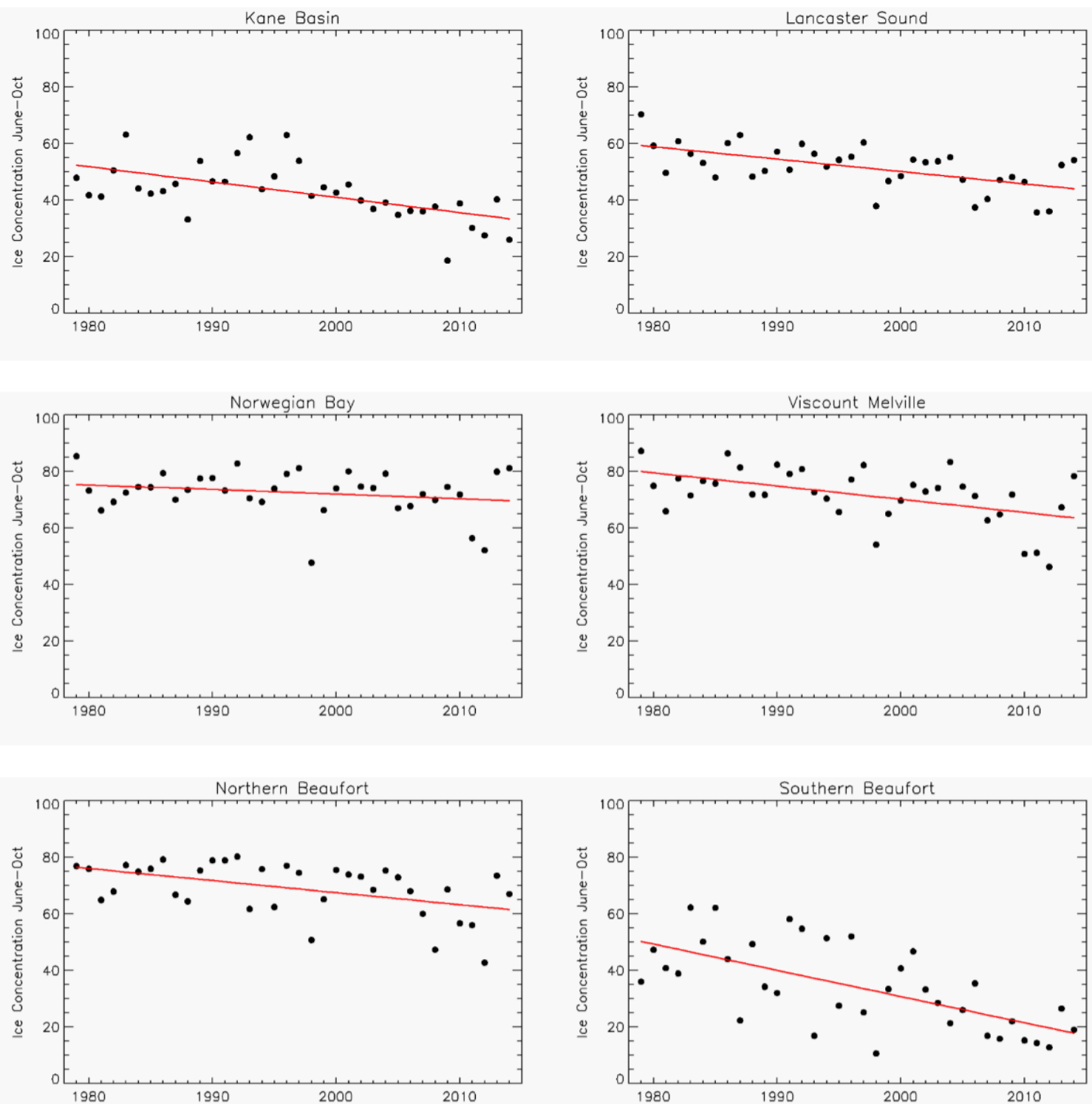

Figure S4. Summer (June through October) sea-ice concentration vs. year, by region (all depths), with least-squares line in red. See Fig. 6 for Baffin Bay region. See Table 3 for trends. 

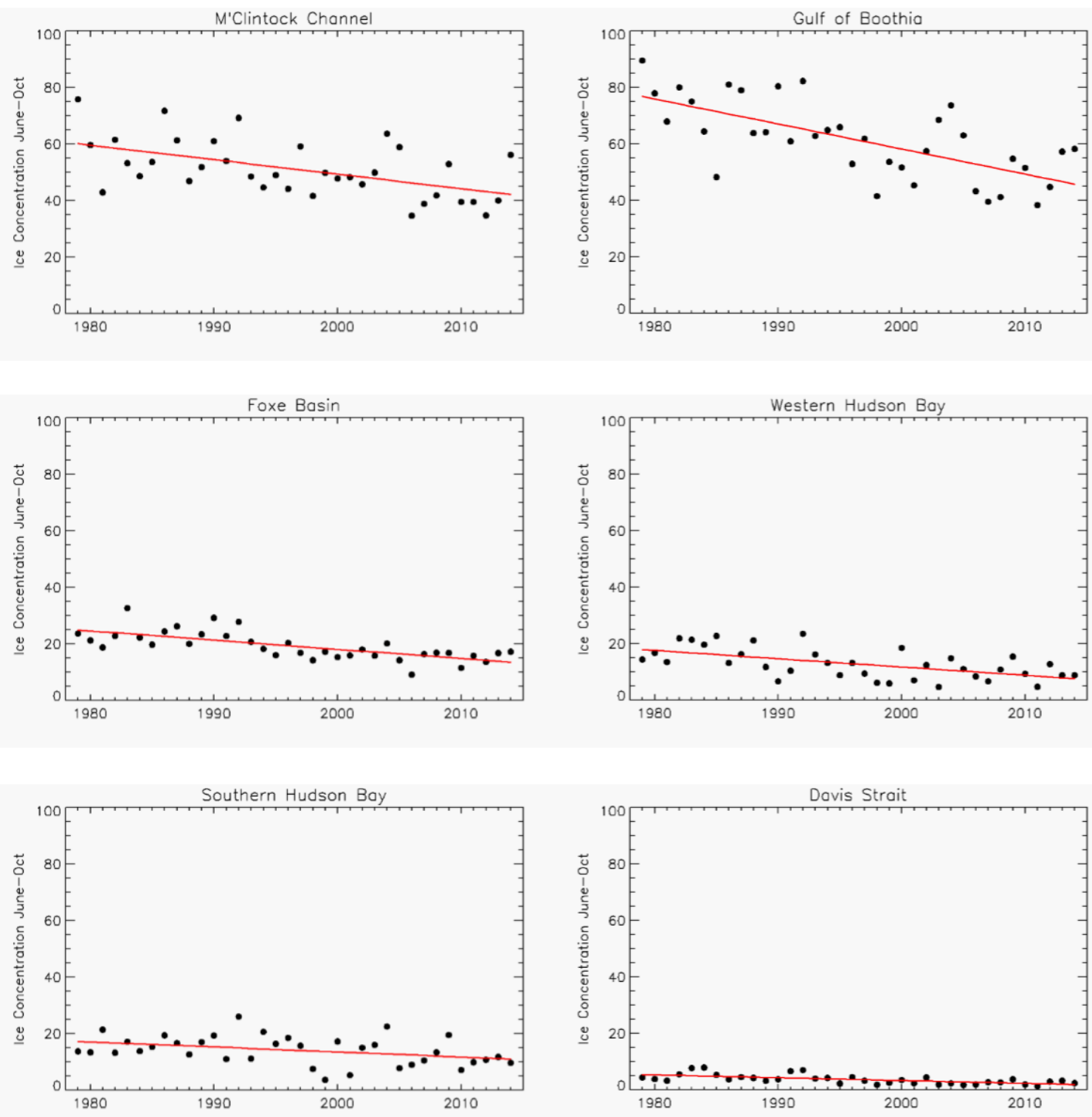

Figure S4 (continued). Summer (June through October) sea-ice concentration, by region. 

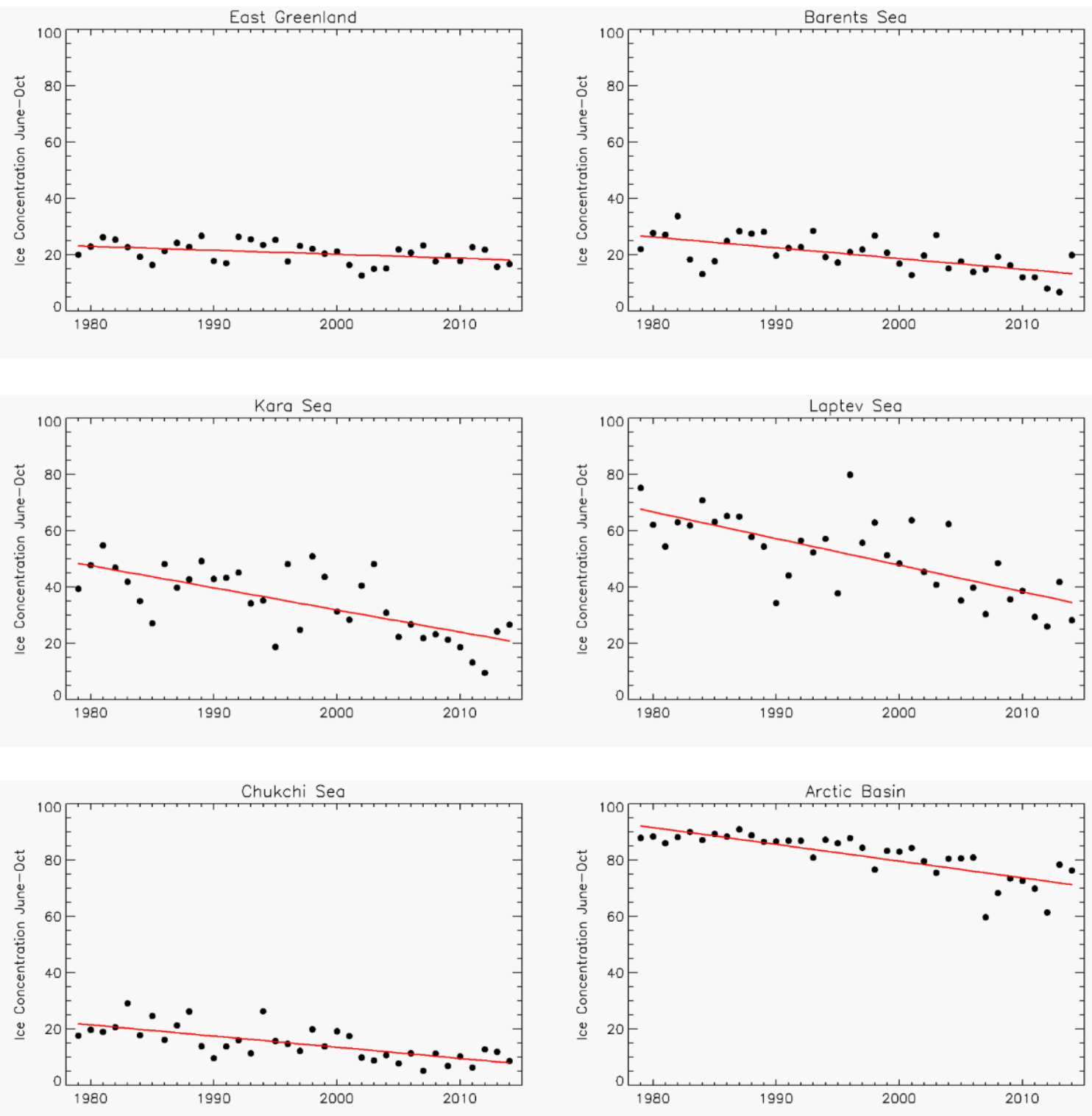

Figure S4 (continued). Summer (June through October) sea-ice concentration, by region. 

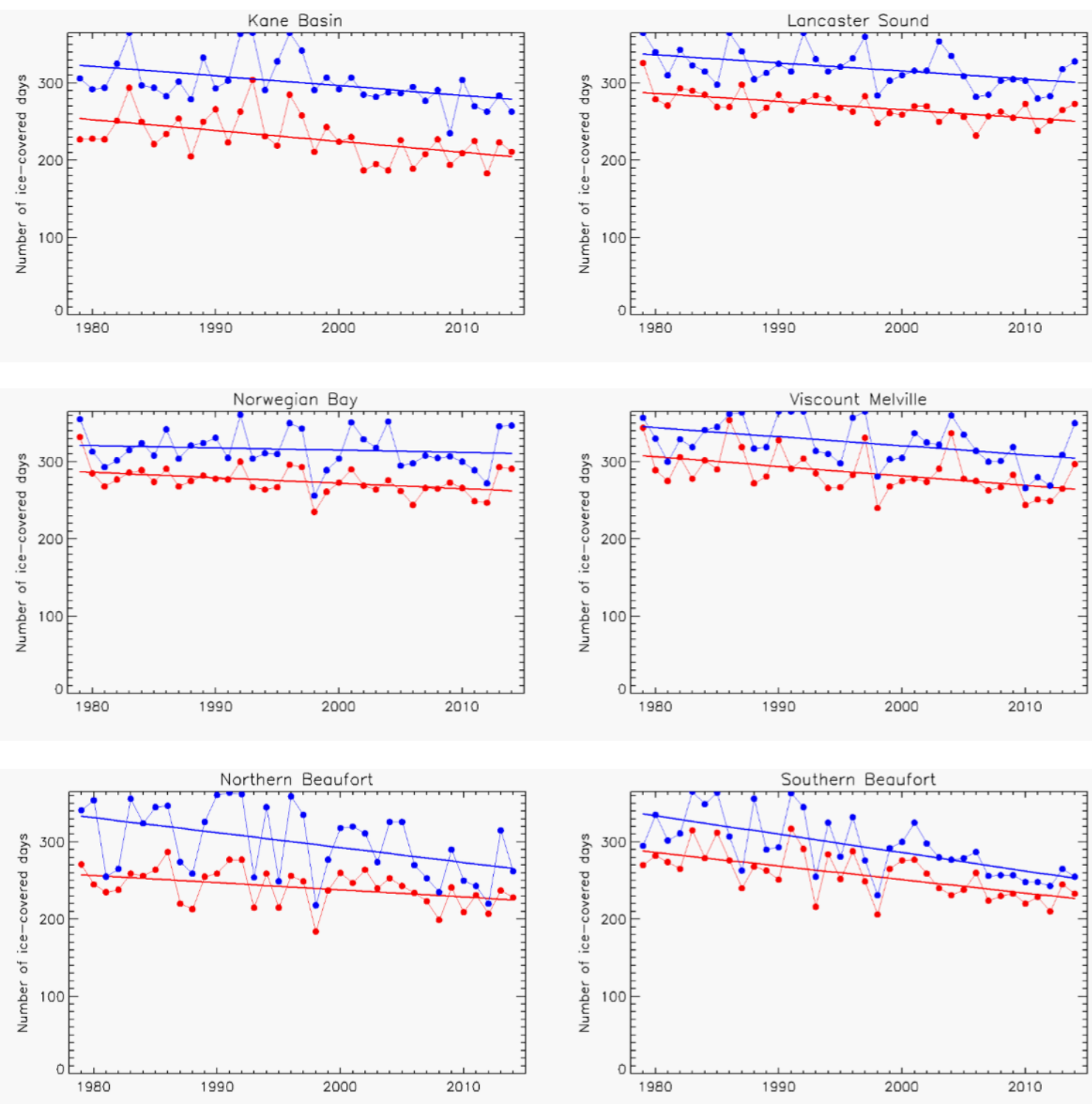

Figure S5. Number of ice-covered days per year, 1979-2014, by region (all depths). An icecovered day is one in which the sea-ice area exceeds a threshold (defined in main text). Blue: number of ice-covered days above $15 \%$ threshold. Red: number of ice-covered days above $50 \%$ threshold. Least-squares lines are also shown. See Fig. 8 for Baffin Bay region. See Table 3 for trends. 

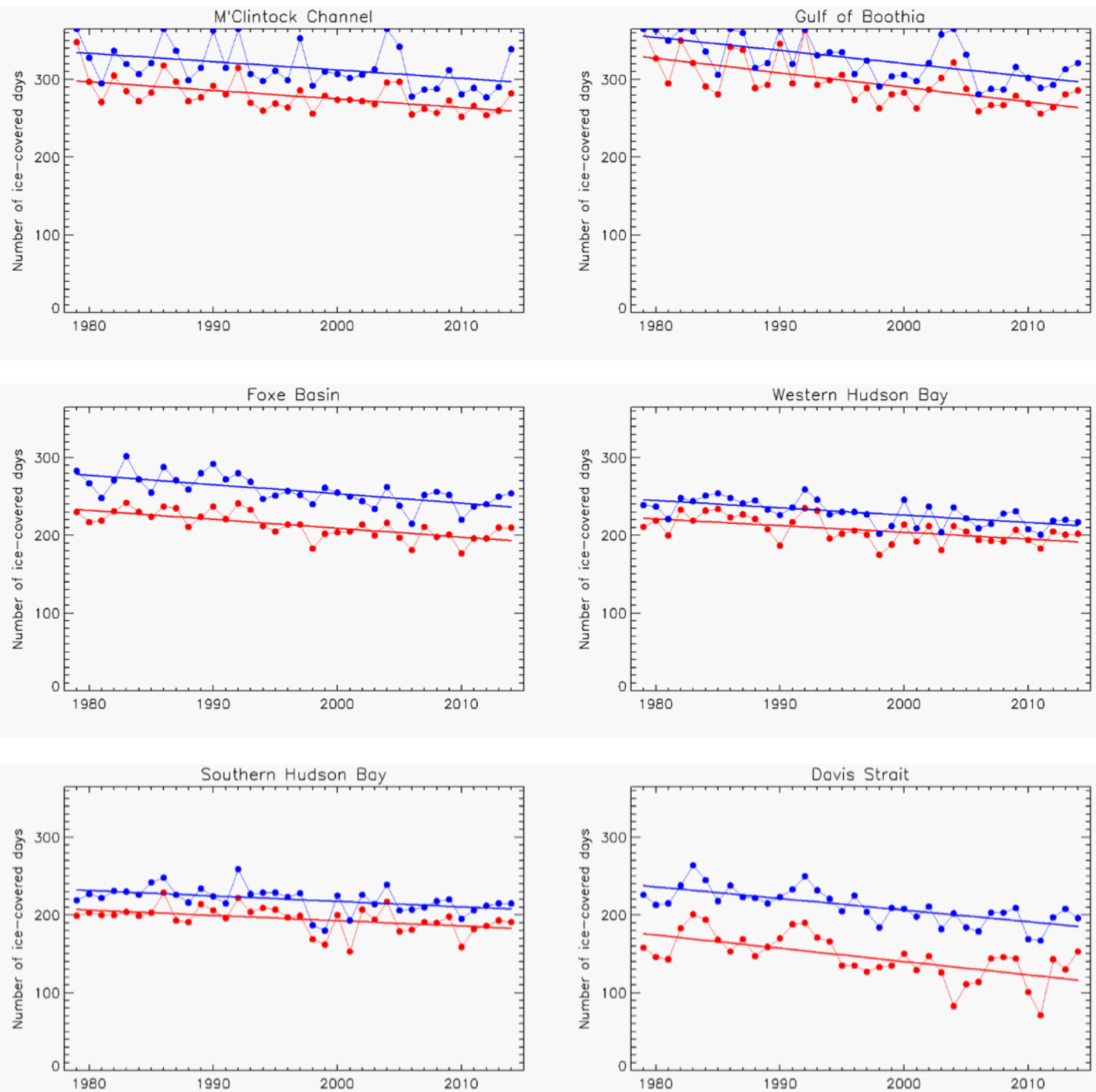

Figure S5 (continued). Number of ice-covered days, by region. 

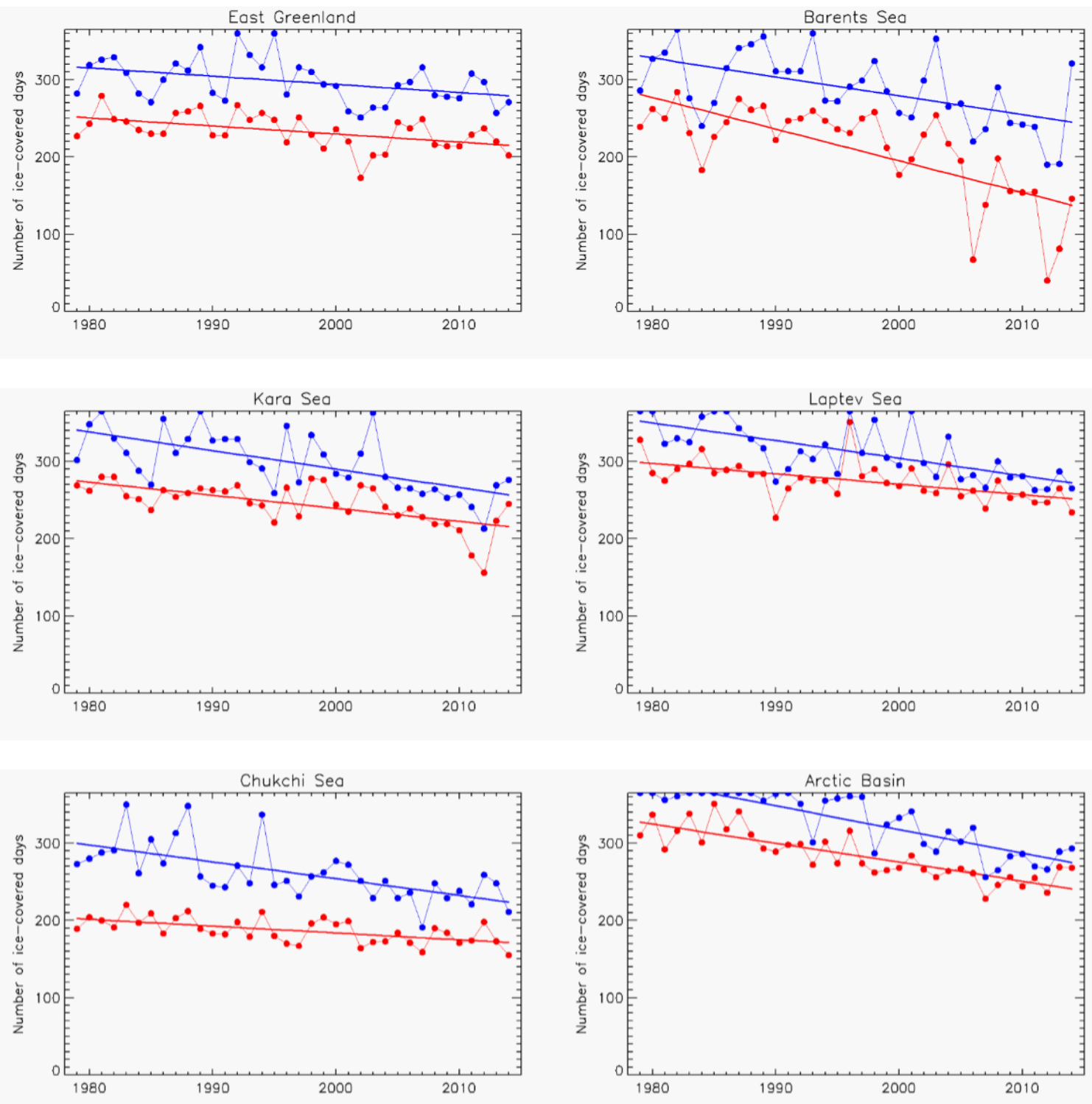

Figure S5 (continued). Number of ice-covered days, by region. 